\title{
Experiências maternas na primeira semana de hospitalização do prematuro em cuidado intensivo
}

Maternal experiences in the first week of the premature hospitalization in intensive care

Las experiencias maternas en la primera semana de hospitalización del prematuro en cuidados intensivos

\section{Cinthia Reis Almeida ${ }^{\mathrm{I}}$, Evanilda Souza de Santana Carvalho ${ }^{\mathrm{II}}$, Silvia da Silva Santos Passos ${ }^{\mathrm{III}}$, Flávia Pimentel Miranda ${ }^{\mathrm{IV}}$, Luciano Marques dos Santos $\mathrm{V}$}

\begin{abstract}
Resumo: Objetivo: descrever a experiência materna na primeira semana de hospitalização do recém-nascido prematuro na unidade de terapia intensiva neonatal. Método: estudo qualitativo, descritivo e exploratório. Os dados foram coletados por meio de entrevista semiestruturada, realizada com dez mães que tiveram parto prematuro no período de julho a novembro de 2015. Utilizou-se a Análise Temática de Bardin. Resultados: cinco categorias de análise retrataram a experiência materna com momentos marcados pela tristeza em ver o filho na unidade pesquisada, o medo de sua morte, a insegurança de manter contato e de participar de seu cuidado e, por fim, as incertezas em saber quando poderia retornar para casa. Conclusão: a experiência materna na primeira semana de hospitalização do recém-nascido prematuro na unidade de terapia intensiva neonatal é marcada pelo sofrimento e pelo medo.
\end{abstract}

Descritores: Enfermagem neonatal; Hospitalização; Mães; Recém-nascido prematuro; Unidades de terapia intensiva neonatal

Abstract: Objective: to describe the maternal experience in the first week of premature newborn hospitalization in the neonatal intensive care unit. Method: qualitative, descriptive and exploratory study. The data were collected through a semi-structured interview with ten mothers who had a premature delivery from July to November 2015. Thematic Analysis of Bardin was used. Results: five categories of analysis portrayed the maternal experience with moments marked by sadness in seeing the child in the unit researched, the fear of his death, the insecurity of

I Enfermeira. Especialista em Saúde da Criança e do Adolescente sob forma de Residência Multiprofissional do Hospital Martagão Gesteira. Salvador, Bahia, Brasil. E-mail: cinthiialmeida@gmail.com. ORCID: 0000-0001-7151-4832.

II Doutora em Enfermagem. Professora. Universidade Estadual de Feira de Santana. Feira de Santana, Bahia, Brasil. E-mail: evasscarvalho@uefs.br. ORCID: 0000-0003-4564-0768.

III Doutora em Enfermagem. Universidade Estadual de Feira de Santana. Feira de Santana, Bahia, Brasil. E-mail: sspassos@uefs.br. ORCID: 0000-0002-2104-5131.

IV Mestra em Medicina e Saúde Humana. Professora. Universidade Salvador. Salvador, Bahia, Brasil. E-mail: flaviabrim@hotmail.com. ORCID: 0000-0001-5508-2056.

V Mestre em Enfermagem. Professor. Universidade Estadual de Feira de Santana. Feira de Santana, Bahia, Brasil. E-mail: luciano.santos@uefs.br. ORCID: 0000-0001-7866-6353. 
Experiências maternas na primeira semana de hospitalização do prematuro em cuidado... $\mid 2$

maintaining contact and of participating in their care and, at last, the uncertainties in knowing when they could return home. Conclusion: the maternal experience in the first week of hospitalization of the premature newborn in the neonatal intensive care unit is marked by suffering and fear.

Descriptors: Neonatal Nursing; Hospitalization; Mothers; Infant, premature; Intensive care units, Neonatal

Resumen: Objetivo: describir la experiencia materna en la primera semana de hospitalización del recién nacido prematuro en la unidad de cuidados intensivos neonatales. Método: estudio cualitativo, descriptivo y exploratorio. Los datos se reunieron mediante una entrevista semiestructurada con diez madres que tuvieron un parto prematuro entre julio y noviembre de 2015. Se utilizó el Análisis Temático de Bardin. Resultados: cinco categorías de análisis retrataron la experiencia materna con momentos marcados por la tristeza de ver al niño en la unidad investigada, el miedo a su muerte, la inseguridad de mantener el contacto y participar en su cuidado y, por último, la incertidumbre de saber cuándo podría volver a casa. Conclusión: la experiencia materna en la primera semana de hospitalización del recién nacido prematuro en la unidad de cuidados intensivos neonatales está marcada por el sufrimiento y el miedo.

Descriptores: Enfermería neonatal; Hospitalización; Madres; Recién nacido prematuro; Unidades de cuidado intensivo neonatal

\section{Introdução}

A ameaça de trabalho de parto prematuro é a indicação mais comum para hospitalização obstétrica pré-natal. ${ }^{1-2}$ É uma experiência que pode impactar de maneira negativa na saúde mental das gestantes. ${ }^{1}$ Dentre as ocorrências registradas nesses momentos, destacam-se o estresse, a ansiedade ${ }^{3}$ e a depressão, ${ }^{3-4}$ devido às preocupações e aos medos relacionados à saúde do bebê, à sua própria saúde e à incerteza sobre o futuro. ${ }^{3}$

Além disso, a notícia da hospitalização do recém-nascido $(\mathrm{RN})$ na Unidade de Terapia Intensiva Neonatal (UTIN) desfaz os sonhos maternos e culmina com sentimento de frustração, infelicidade e culpa, sendo uma condição difícil que rompe os planos almejados e impacta na perda do sonho da maternidade, do filho idealizado. ${ }^{5}$ Ter um bebê hospitalizado na UTIN é uma experiência desgastante para as mães, sendo resultado da exposição a diferentes estressores relacionados à condição do recém-nascido prematuro (RNPT), alteração no papel materno, no ambiente ou na equipe da unidade de UTIN. Esses fatores potencializam efeitos psicológicos negativos, além do desenvolvimento interrompido do apego adequado entre mãe e filho. ${ }^{6}$ 
Em estudo anterior, os sentimentos vivenciados pelas mães, relacionados à prematuridade dos filhos, revelou também angústia, medo e estranhamento, ao terem contato pela primeira vez com a UTIN. Ao olharem o bebê, as mães precisaram adaptar-se à imagem real, que, muitas vezes, não foi semelhante à fantasiada por elas durante a gestação. ${ }^{7}$

Soma-se a isso, o ambiente da UTIN, considerado hostil tanto para o RN hospitalizado como para a mãe, que o percebe como assustador e desagradável, ${ }^{7}$ principalmente durante a primeira semana de hospitalização do RNPT. Além disso, observam-se outras combinações de sentimentos vivenciadas pelas mães, como insegurança e impotência, pois esperam permanecer ao lado dos filhos após o parto e, diante dessa situação, tornam-se expectadoras do cuidado, reforçando a dependência do RN à assistência da equipe da UTIN. ${ }^{8} \mathrm{Na}$ primeira semana de hospitalização do RNPT na UTIN, as puérperas imergem em uma atmosfera de incerteza, desorientação e incapacidade para pensar com clareza. ${ }^{9}$

Frente a tal situação, torna-se fundamental um olhar sobre as mães que estão vivenciando a prematuridade e hospitalização dos filhos e incluir suas demandas de cuidado no plano assistencial. No contexto brasileiro, entretanto, ainda é incipiente a produção do conhecimento sobre a experiência materna na primeira semana de vida do RNPT. Conforme dados de uma revisão integrativa realizada em $2016,{ }^{10}$ os estudos publicados focam a experiência de forma ampla, o que justificou a realização da presente pesquisa. Tendo em vista que este é o período no qual podem ocorrer rápidas e profundas mudanças cognitivas, afetivas e comportamentais na experiência materna, já que esta é o principal membro familiar que permanece constantemente na UTIN e atua como elo entre os demais familiares e o RNPT, torna-se necessário compreender como se dá esta experiência na sua perspectiva. Assim, este estudo busca responder a seguinte questão: como se dá a experiência materna durante a primeira semana de hospitalização do recém-nascido prematuro na UTIN? Este estudo objetivou descrever a experiência materna na primeira semana de hospitalização do RNPT na UTIN. 
Experiências maternas na primeira semana de hospitalização do prematuro em cuidado... | 4

\section{Método}

Trata-se de um estudo qualitativo, descritivo e exploratório, vinculado a uma pesquisa multicêntrica, realizada em quatro estados brasileiros: Rio Grande do Sul, Paraná, Bahia e Rio Grande do Norte. Neste artigo, são apresentados os dados coletados nas UTIN de dois hospitais públicos do município de Feira de Santana, Bahia, incluídas por serem as unidades de referência no atendimento de RNPT na região. Nas unidades pesquisadas, a puérpera era o único membro da família do RNPT com acesso livre à UTIN no período da coleta de dados. A entrada do pai e de pessoas significativas para a família era possibilitada em turnos e horários restritos e em poucos dias da semana.

Participaram 10 mulheres (seis entrevistadas em um hospital e quatro no outro) que acompanharam a primeira semana de hospitalização do RN na UTIN e tiveram parto prematuro (<37 semanas). Elas foram assim classificadas pela Idade Gestacional (IG) obtida com a Data da Última Menstruação (DUM), ou com a ecografia realizada até 20 semanas, ou ainda pelo método de Capurro Somático, no qual ${ }^{11}$ são avaliadas cinco características físicas do RN (formato da orelha, tamanho da glândula mamária, formação da aréola mamária, textura da pele e as pregas plantares), a fim de identificar a IG e o risco ao nascer. Assim, participaram do estudo puérperas escolhidas de forma aleatória. Foram definidos como critérios de inclusão: ter parto entre 20 e 36 semanas e 6 dias de gestação e o concepto pesando mais que 500 gramas; ter o RNPT hospitalizado na UTIN por sete dias ou mais; ter acompanhado a hospitalização do RNPT na UTIN; não apresentar problemas clínicos e obstétricos; e apresentar condições psicológicas para responder a entrevista.

A coleta de dados foi realizada no período de julho a novembro de 2015, por meio de entrevistas semiestruturadas. As participantes foram estimuladas a responder as seguintes questões norteadoras: "Como a senhora se sentiu ao saber que seu filho seria hospitalizado na UTIN?”; “Como está sendo/ou como foi para a senhora a experiência na primeira semana de hospitalização do seu filho na UTIN?”. 
5 | Almeida CR, Carvalho ESS, Passos SSS, Miranda FP, Santos LM

As entrevistas foram realizadas enquanto os bebês estavam hospitalizados. Entretanto, alguns já haviam recebido alta da UTIN e foram transferidos para acompanhamento de ganho de peso na Unidade Canguru. Visando não atrapalhar a rotina das participantes, as entrevistas foram agendadas de acordo com sua disponibilidade, em locais reservados nas enfermarias e contando com a presença apenas da entrevistadora, após a assinatura do Termo de Consentimento Livre e Esclarecido (TCLE). Foi utilizado um gravador digital para capturar as falas das entrevistadas.

A coleta foi encerrada ao se alcançar a saturação do conteúdo dos depoimentos, isto é, informações $^{12}$ novas possivelmente encontradas nas entrevistas não mudariam de forma relevante os resultados já obtidos, tornando improdutiva a continuidade da coleta. As entrevistas foram transcritas na íntegra e receberam correções ortográficas, de acordo com a anuência das entrevistadas. Inicialmente, o material coletado foi organizado com o objetivo de conhecer seu conteúdo. Na sequência, o material empírico foi lido de forma profunda, sendo identificadas palavras ou expressões que apareciam nos textos com frequência, as quais foram agrupadas em 14 unidades de significados que compuseram a base para a elaboração das unidades de significação. Estas originaram as cinco categorias da pesquisa, para compreender o objeto do estudo. $\mathrm{Na}$ apresentação dos dados, foram escolhidas as falas mais representativas de cada categoria, evitando-se repetições de elementos comuns.

A análise dos dados foi realizada por meio da análise temática de Bardin, na qual o conceito central é o tema, seguindo-se as etapas de pré-análise (fase de organização), exploração do material, tratamento dos resultados obtidos e interpretação. ${ }^{13}$

Este estudo atendeu às recomendações da Resolução nº 466/2012, no que diz respeito à ética em pesquisa envolvendo seres humanos. Foi aprovado pelo Comitê de Ética e Pesquisa da Universidade Estadual de Feira de Santana (CEP/UEFS), por meio do Parecer nº 643.668, em 12 de maio de 2014.

\section{Resultados}


Experiências maternas na primeira semana de hospitalização do prematuro em cuidado... $\mid 6$

Entre as 10 mães que participaram da pesquisa, nove viviam com o companheiro, cinco possuíam mais de um filho que estavam em casa sob os cuidados de outros familiares e todas encontravam na família uma fonte de apoio durante o processo de hospitalização. A experiência materna na primeira semana de hospitalização do RNPT nas UTIN pôde ser compreendida por meio das categorias apresentadas a seguir, que emergiram do material empírico: Uma experiência inicialmente difícil; Sofrimento ao ver o RNPT em uso de tubos e aparelhos; Medo da morte do RNPT; Não realização de contato físico e cuidados com o RNPT; Sofrimento por não saber quando o RNPT sairá da UTIN.

\section{Uma experiência inicialmente difícil}

Inicialmente, a experiência materna foi marcada por intenso sofrimento diante do filho pré-termo e da consequente hospitalização na UTIN. Isso decorre do fato de a prematuridade romper com a idealização de ter um bebê saudável e de levá-lo para casa após o parto. Por isso, é difícil para a mãe acreditar na realidade vivenciada, como é evidenciado nos depoimentos a seguir:

[...] a experiência de ter meu bebê na UTIN [Unidade de Terapia Intensiva Neonatal] está sendo um pouco difícil de acreditar ainda, porque eu esperava ter em janeiro, só que aconteceu antes, três/quatro meses antes [...]. Não tem explicação. Eu não esperava ter um filho prematuro, e eu não esperava nunca acontecer comigo, principalmente a primeira filha. (E1)

[...] eu não desejo para ninguém ter um filho hospitalizado na UTI[Unidade de Terapia Intensiva] porque é difícil saber que não vai levar para casa, saber que não está bem ainda [...]. É difícil, por não levar comigo no momento que nasceu. (E2)

[...] tinha vezes que eu chorava, perguntava a Deus o porquê, porque isso estava acontecendo comigo [...]. (E7)

Soma-se a isso, a perturbação do domínio cognitivo materno nos primeiros dias da hospitalização, levando-as na direção do não entendimento das informações repassadas pela 
equipe sobre o estado clínico do RNPT. Entretanto, apesar de não compreenderem a situação vivenciada, as mães desejavam estarem presentes na UTIN.

[...] a gente não entende por que está ali. Os médicos explicam, mas a gente não entende. Mãe quer estar com ela no colo. (E2)

Neste sentido, a experiência na primeira semana de hospitalização do RNPT foi considerada difícil pelas entrevistadas, por interromper todos os planos idealizados e por desencadear na mãe fontes iniciais de sofrimento que se adicionaram às peculiaridades da hospitalização e do estresse que o ambiente da UTIN provoca.

\section{Sofrimento ao ver o RNPT em uso de tubos e aparelhos}

Ao entrar na UTIN e ver o filho prematuro invadido por tubos, sondas, cateteres e cercado de máquinas utilizadas como suporte terapêutico desconhecido, a mãe sentiu-se amedrontada.

[...] só fiquei assustada quando eu vi que ela estava com o tubo na boca. (E2)

Ao presenciar os procedimentos invasivos realizados no cuidado do RNPT, as mães sentiram-se tristes, por acreditarem que os filhos estavam sofrendo.

[...] triste por ver ela na UTI[Unidade de Terapia Intensiva], porque todo dia a fura [referindo-se aos procedimentos invasivos, como a punção venosa]. (E3)

[...] ele ficou respirando por aparelho. E aí, quando eu ia vê-lo, eu sentia que ele ficava incomodado, se torcendo todo ali para mim. Era mais um motivo de tristeza ainda. (E4)

Como consequência, uma das mães adotou como estratégia inicial a realização de questionamentos para os membros da equipe de saúde da UTIN sobre a situação do filho, na 
tentativa de se habituar, compreender a finalidade de cada aparelho, acostumar-se e manter-se tranquila durante a experiência.

[...] ao mesmo tempo, me dava agonia de ver aqueles tubos na boca dele. Aí perguntei se esses tubos não ferem a boca dele. Aí a enfermeira disse que não. É tanto que ele tinha que ficar sedado um pouquinho, para não ficar se mexendo. (E8)

Assim, as tecnologias e dispositivos utilizados como suportes na assistência ao RNPT e a complexidade do cuidado impactaram no estado afetivo das mães, que vivenciavam diversos sentimentos, a exemplo do medo constante de perder o filho.

\section{Medo da morte do RNPT}

As entrevistadas perceberam a UTIN como um local no qual as pessoas estão mais próximas da morte ou em estado crítico de saúde, o que potencializou a vivência do medo da perda do filho prematuro.

[...] a UTI [Unidade de Terapia Intensiva] é um nome muito pesado e para uma criança que nasceu fora do tempo. Para mim, ali já era um risco ir para UTI, então foi forte. Porque, quando falam "ir para UTI”, a pessoa pensa que já está em caso grave. (E1)

Esse sentimento foi mais intenso quando as entrevistadas vivenciaram intercorrências clínicas que demandaram intervenções imediatas dos membros da equipe de saúde, a exemplo da reanimação neonatal.

[...] ele chegou a sangrar duas vezes pelo tubo. Eu o vi totalmente parado, quase morto. Eu vi ali que meu filho não estava bem, foi que eles [a equipe] foram fazendo massagem e eu fiquei vendo tudo. Aí, quando eu cheguei aqui em cima, desabei, comecei a chorar [...]. Eu senti que ia perder meu filho, ia perder ele. Ele ficou mais de uma hora, desacordado, sem respirar. (E4) 
9 | Almeida CR, Carvalho ESS, Passos SSS, Miranda FP, Santos LM

Ainda durante a experiência de hospitalização do RNPT, as mães vivenciaram o medo constante de perda, devido à sua instabilidade e gravidade clínica, pensando que a qualquer momento receberiam alguma notícia ruim.

[...] foi um desespero toda vez que chegava na UTI [Unidade de Terapia Intensiva] e tinha notícia ruim. O desespero era porque eu ficava com medo dela morrer. (E9)

[...] chorei com medo daquele momento dela se apagar. (E10)

Desta maneira, a pressão constante provocada na figura materna, por estar em um local desconhecido e percebido como um espaço de RN com condições clínicas instáveis e cada vez mais graves, afetavam profundamente a condição cognitiva das mães, potencializando, a seguir, seu distanciamento inicial do filho, evidenciado pela insegurança em tocá-lo.

\section{Não realização de contato físico e cuidados com o RNPT}

Por perceber o RNPT como um ser pequeno e frágil, a mãe sentiu inicialmente medo de manter contato com o filho. Postergou este cuidado, por acreditar que seu toque poderia desconectar tubos, fios e aparelhos e modificar sua condição clínica. Assim, por um momento, as tecnologias que garantiam a vida do RNPT foram percebidas, nos depoimentos das entrevistadas, como barreiras iniciais na aproximação entre mãe e filho, interferindo no fortalecimento do vínculo após o nascimento.

[...] mas eu fico com medo, porque tenho medo de desmanchar [referindose a causar alteração clínica]. Ela é muito frágil. (E2)

[...] eu fiquei com medo de pegá-la no começo. Eu nem mexia nela, porque ela ficava na incubadora. Minha mãe me ligava e perguntava, e eu dizia: 
Experiências maternas na primeira semana de hospitalização do prematuro em cuidado... $\mid 10$

mãe, eu não mexo nela. Eu tenho medo de desconectar alguma coisa lá. Daí minha mãe falava: vai ficar tudo bem. Tem que mexer [referindo-se a tocar na criança]. (E6)

A decisão quanto a não tocar no RNPT, provocada pela crença de que ocasionaria prejuízos na sua condição clínica, limitou, na primeira semana, a participação materna nos cuidados de menor complexidade, como, por exemplo, a troca de fraldas.

[...] ainda não troquei fralda. Já vi trocando, mas não consigo. Eu tenho medo de machucar. Eu toco assim: abro a portinha [da incubadora], fico alisando-o, mas pegar mesmo para trocar fralda, não dá. Já troquei de dois filhos, mas eles foram de nove meses. Esse é muito frágil. Ele não está totalmente formado ainda. (E4)

A ausência de contato físico e o fato de não poder amamentar o filho tornaram a experiência materna ainda mais difícil. Mesmo desejando oferecer seu leite como nutrição, este cuidado ocorreu de maneira indireta, por meio da ordenha, tendo em vista as condições clínicas do RN e sua ausência de prontidão para a amamentação. Esta impossibilidade inicial dificultou o fortalecimento do vínculo entre mãe e filho.

[...] ainda não segurei, desde o dia que tirou ele [referindo-se ao parto]. Não pode segurar ainda, nem mamar no peito. (E8)

[...] difícil por não amamentar. A gente tira o leite, mas não é o mesmo que colocar no peito e sentir. É ruim!(E2)

[...] ele está em dieta zero. É difícil, porque tem alguns bebês ali na UTI que podem mamar, que já saiu da dieta zero, e ele não. Ele ainda está na dieta zero. Aí é difícil. (E5)

[...] primeiro eles [equipe multiprofissional] falaram que não iria poder dar o leite, porque ficou na dieta zero e depois ficou tomando do hospital. Agora, todo dia 6 h, eu tiro para ela. (E3) 
A ausência de contato físico da puérpera com o filho, em meio aos desafios enfrentados na primeira semana de hospitalização na UTIN, associada às incertezas quanto ao prognóstico e alta do RNPT, foram fontes adicionais de ansiedade e sofrimento materno por não saberem quando poderiam retornar para casa, retomar sua rotina e o convívio com os familiares.

\section{Sofrimento por não saber quando o RNPT sairá da UTIN}

As incertezas quanto ao futuro do filho, o dia da alta da UTIN e o retorno para casa intensificaram o sofrimento materno e a ansiedade por informações e respostas que nem mesmo a equipe saberia lhes dar.

[...] foi uma experiência difícil, por causa do tempo que ela passou na UTI [Unidade de Terapia Intensiva]. Eu esperava que ela passasse pouco tempo. A médica me falou que era só por causa do peso, no máximo 15 dias ela estaria em casa e isso não aconteceu. Ela passou 45 dias. Foi difícil, porque ela ficou mais tempo do que eu imaginava. O sentimento de dor enquanto ela estava na UTI, foi por eu sempre perguntar quanto tempo faltava para ela sair de lá e nunca tinha uma resposta, porque eles também não sabiam. (E1)

Ademais, a permanência em tempo integral no hospital para acompanhar o filho prematuro, longe de familiares e amigos, também contribuiu com um intenso sofrimento, mobilizando a mãe a desejar retornar para a normalidade que sua vida possuía antes da experiência do nascimento prematuro e hospitalização do filho no cuidado intensivo neonatal.

[...] estou sentindo muita falta da minha casa, muita saudade [...] (E10)

[...] ter que ficar aqui no hospital, uma preocupação de ter que ficar aqui [...] A experiência de ter meu bebê na UTI [Unidade de Terapia Intensiva], eu nunca pensei que ia passar na minha vida. É difícil ficar aqui, ficar longe de todo mundo, longe de casa. (E5) 
Experiências maternas na primeira semana de hospitalização do prematuro em cuidado... | 12

Assim, a vontade materna foi de levar o filho logo para casa, na tentativa de encerrar o sofrimento ocasionado pela hospitalização na UTIN.

[...] dá vontade de pegar e levar ele para casa. (E5)

\section{Discussão}

A experiência materna, na primeira semana de hospitalização do RNPT na UTIN, foi inicialmente traduzida como muito difícil, por romper a idealização de um filho saudável, gerando tristeza devido à impossibilidade de cuidar e levá-lo para casa após o parto. ${ }^{14}$ Assim, a vivência materna foi marcada por intenso sofrimento, dificuldade para acreditar que a hospitalização estava acontecendo e profunda perturbação cognitiva e afetiva que repercutiu na ausência de entendimento sobre as informações que eram repassadas.

Neste estudo, as mães sofreram ao ver e acompanhar a hospitalização dos filhos e tiveram dificuldades para aceitar e entender os motivos da permanência na UTIN. Como já abordado em outra pesquisa, a experiência de vivenciar a hospitalização do RNPT configura-se como um tormento, marcado por tensões e estresse, que podem interferir na saúde física e mental materna. ${ }^{15}$ Nesse cenário, a vivência da maternidade era marcada por sentimentos de insegurança e medo sobre a sobrevivência do filho. ${ }^{5}$

Por isso, é necessário que os profissionais de saúde da UTIN identifiquem, nos primeiros dias de hospitalização do RNPT, a rede de apoio e o suporte social materno utilizado em tempos difíceis e utilize-os como estratégias para o seu cuidado. Além disso, torna-se fundamental oferecer apoio emocional para essas mulheres, desde os primeiros momentos de sua entrada na UTIN, por profissional devidamente qualificado.

Além do estranhamento e o impacto causado pelo ambiente da UTIN, o sofrimento ao ver o RNPT em uso de tubos e aparelhos, foi manifestado pelo relato materno de medo desses 
recursos, por não os conhecer. A utilização desses, embora necessária à manutenção do suporte de vida dos $\mathrm{RN}^{5,14}$ estimula indagações maternas e o receio sobre as reais chances de sua sobrevivência, ${ }^{5,9,16}$ intensificando o estresse ${ }^{17}$ e o sofrimento da puérpera durante os primeiros dias de hospitalização. ${ }^{14}$

Outra fonte de sofrimento materno revelada neste estudo, que dificultou a experiência na primeira semana de hospitalização do RNPT na UTIN, foi ter presenciado procedimentos invasivos. Essa visão gerou tristeza nas mães, pois pensaram que os RNPT estivessem sofrendo. Presenciar a realização desses procedimentos proporciona apreensão materna, devido à preocupação com o estado de saúde do RNPT. O medo decorre da crença de que a utilização desses recursos se relaciona ao agravamento da condição clínica do $\mathrm{RN}$, potencializando, assim, uma experiência muito dolorosa e de sofrimento para o filho, o que faz a mãe sentir-se ainda mais triste. ${ }^{14}$

Mães de uma pesquisa realizada em Gana indicaram que, embora muitas vezes fossem informadas dos procedimentos a serem executados em seus bebês, eles não foram explicados. Isso, em alguns momentos, deixou-as ansiosas, especialmente quando supunham que os procedimentos estavam sendo realizados porque a condição clínica do RN estava se deteriorando. ${ }^{18}$

Alguns estudos nacionais ${ }^{19-20}$ realizados com pais de RN em UTIN, por meio da aplicação da versão brasileira da Parental Stress Scale: Neonatal Intensive Care Unit (PSS: NICU), demonstraram que a alteração no papel de mãe/pai foi a subescala em que se obteve o maior nível de estresse, o que foi também observado em pesquisa realizada na Turquia. ${ }^{17} \mathrm{Na}$ referida escala, um dos itens mais frequentemente sinalizados foi sentir-se desamparada e incapaz de proteger o RN da dor e de procedimentos dolorosos. ${ }^{19}$

Naquele estudo, a subescala "Aparência e o Comportamento do Bebê", foram consideradas situações mais estressantes: "Quando o meu bebê parecia estar sentindo dor" e "Quando meu bebê parecia triste". ${ }^{19}$ Nesta subescala, os escores mais altos de estresse foram identificados nas entrevistadas que não possuíam experiência prévia com prematuridade. ${ }^{20}$ 
Experiências maternas na primeira semana de hospitalização do prematuro em cuidado... $\mid 14$

Nestas, destacaram-se dados relacionados a "Sons e Imagens", "Ver uma máquina (respirador) respirar pelo meu bebê" e "O barulho repentino do alarme dos monitores". ${ }^{19}$

Neste sentido, mesmo diante de intenso medo e sofrimento, a estratégia utilizada pelas entrevistadas foi buscar informações dos profissionais de saúde sobre as condições do filho. As informações fornecidas pelos profissionais de saúde, juntamente com o conhecimento progressivo dos protocolos de trabalho e do ambiente da UTIN, foram primordiais para promover a tranquilidade materna. ${ }^{16}$

O medo da morte do RNPT foi um tema frequente nas falas das entrevistadas. Este medo esteve associado à crença de que a UTIN seria um local para bebês graves. ${ }^{5}$ Para as entrevistadas, a hospitalização nessa unidade acontece devido às condições clínicas graves do RNPT, tendo, assim, maior probabilidade de morte do que sobrevivência, o que provocava intensa preocupação. ${ }^{14,16}$ Sendo assim, a UTIN era percebida pelas mães como um ambiente enigmático e ameaçador, que aumentava o medo e prolongava suas incertezas ${ }^{16}$ quanto ao que iria acontecer.

O medo da morte também decorreu da instabilidade clínica do RNPT. Assim, a sensação de perda do filho foi outro elemento muito presente na experiência materna durante os primeiros dias de internação na UTIN., ${ }^{5,21}$ O medo de receber alguma notícia ruim a qualquer instante esteve presente nessa experiência. As informações sobre as alterações no quadro clínico fizeram emergir momentos intensos de apreensão, angústia, sensação de impotência e incerteza quanto ao futuro ${ }^{5}$ do RNPT, devido à sua imaturidade orgânica. As mães sentiam que a qualquer momento o quadro clínico poderia agravar, emergindo o medo de perdê-los.

Reforçando esses achados, em pesquisa semelhante, foram observadas diversas reações iniciais diante da hospitalização, como sentimentos de desespero e procura por informações sobre o quadro clínico, bem como o diagnóstico, possíveis complicações e prognóstico. ${ }^{22}$ Assim, para fortalecer o vínculo de confiança entre a equipe e a puérpera, é necessário que os profissionais se comuniquem de forma efetiva e constante, e que sejam sensíveis e saibam 
escolher as palavras adequadas, evitando desfazer as expectativas positivas criadas em relação à evolução do RNPT. ${ }^{5}$

Por isso, é importante que os profissionais de saúde orientem as puérperas, já nos primeiros dias de hospitalização do RNPT na UTIN, sobre aparelhos e dispositivos utilizados, esclarecendo que são necessários como suportes para sua recuperação e que também possam dirimir as dúvidas relativas à crença de sofrimento associada ao uso desses recursos. Para tanto podem ser utilizadas diversas estratégias que colaborem para a apreensão dos conhecimentos necessários, a exemplo de livros, vídeos, fotografias, folhetos ou cartilhas informativas. É também primordial fornecer informações claras sobre a evolução clínica diária do RNPT.

A insegurança demonstrada também pelas mães neste estudo, para manter contato com os RNPT e participar dos cuidados de menor complexidade, em meio às privações de não poder cuidar como de fato gostariam, deriva da forma de enxergá-los como seres frágeis. Este medo também decorreu da percepção de que o toque poderia desconectá-los dos aparelhos e dispositivos e provocar instabilidade clínica.

Pesquisas demonstraram que, na primeira vez em que as mães entraram na UTIN para ver os filhos, ficaram chocadas com a sua aparência física e sentiram medo, ${ }^{16}$ devido ao tamanho minúsculo ${ }^{5,9}$ e vulnerabilidade. ${ }^{14}$ Essas constituem as impressões visuais com maior impacto na experiência materna, ${ }^{5}$ que potencializam ainda mais o seu sofrimento ${ }^{14}$ e acentuam as dúvidas sobre as reais chances de sobrevivência do bebê. ${ }^{9}$

Esses achados corroboram os de outro estudo, que revelou, nas falas das mães, sentimentos de impotência dentro da UTIN, pela impossibilidade de realizar cuidados básicos com os bebês, como amamentar, pegar no colo e dar banho. ${ }^{23}$ Além disso, o sentimento de medo materno de tocar e acariciar os filhos foi explicado pela autoestima comprometida, pelo próprio ambiente do cuidado intensivo e também pela ausência de autoconfiança em sentirem-se capazes de cuidar daquele ser. ${ }^{24}$ 
Experiências maternas na primeira semana de hospitalização do prematuro em cuidado... $\mid 16$

Em alguns estudos, a UTIN foi percebida pelas puérperas como um espaço ameaçador para a relação mãe-filho, pois algumas barreiras iniciais podiam impedir o contato físico entre ambos, ${ }^{14}$ como o medo de interferir no suporte tecnológico ou de transmitir infecção, ${ }^{16}$ o que poderia causar mais problemas em seu estado crítico de saúde. ${ }^{9,14}$ Contudo, a primeira visão dos bebês era o ponto de partida para que as mães pudessem lidar com a realidade e aceitá-los, independentemente de suas características. ${ }^{18}$

Outro fator gerador de sofrimento para a mãe foi a impossibilidade de amamentar o filho, dificultando a formação do vínculo entre eles. De modo análogo, pesquisa qualitativa anterior revelou dificuldades enfrentadas pelas mães durante a hospitalização dos filhos, devido ao distanciamento e à impossibilidade de prestar cuidados diretos a eles. ${ }^{25} \mathrm{O}$ pequeno tamanho e a fragilidade dos RNPT, assim como os equipamentos e dispositivos, podem dificultar o processo de amamentação. ${ }^{9}$

Neste sentido, as mães da presente pesquisa não amamentaram nos primeiros dias de hospitalização dos filhos na UTIN devido às suas condições clínicas, o que foi fonte de sofrimento materno. O caos emocional vivido pelas mães dos RNPT diminui suas habilidades para controlar a situação e repercute no início da lactação de maneira incomum, por meio do uso de uma bomba em sua mama, contudo o leite configura-se como estratégia para se manterem emocionalmente conectadas ao bebê. ${ }^{9}$

As mães revelaram também incertezas em saber o futuro dos RNPT e quando poderiam retornar para as suas casas e famílias, o que contribuiu para gerar ansiedade na obtenção de informações e de mais sofrimento. Ter um filho em UTIN e viver a maternidade nesse cenário gera sentimentos de medo, insegurança, incerteza ${ }^{5}$ e constante preocupação com a sobrevivência do $\mathrm{RN},{ }^{5,14}$ sendo essa uma situação muito difícil. ${ }^{14}$

Ademais, foi observado, nesta pesquisa, que o distanciamento da família também constituiu um intensificador do sofrimento materno e do desejo de retornar para casa. Em outra 
17 | Almeida CR, Carvalho ESS, Passos SSS, Miranda FP, Santos LM

pesquisa, ao acompanharem os filhos hospitalizados na UTIN em tempo integral, as mães relataram um rompimento de vivências e rotinas anteriores à hospitalização, além da saudade do convívio com os familiares. ${ }^{26}$

Assim, é essencial que os profissionais de saúde da UTIN desenvolvam estratégias e programas de intervenção que ajudem as mães a diminuir o estresse de sua experiência na primeira semana de hospitalização do RNPT e apoiem-nas no enfrentamento dessa situação. ${ }^{6}$ Para tanto, são necessárias, no contexto pesquisado, transformações cotidianas baseadas no acolhimento efetivo às mães dos RNPT, atendendo as suas demandas durante a hospitalização, além de engajá-las e incluí-las na assistência prestada aos filhos, ${ }^{27}$ considerando-as como uma unidade básica e fundamental do cuidado dos novos membros do sistema familiar e constante em sua vida, mesmo que no contexto adverso da UTIN.

Além disso, é necessário inserir a mãe o mais precocemente possível no cuidado ao RN, encorajando-a e apoiando-a emocionalmente, para que a experiência de acompanhar o filho na sua primeira semana de hospitalização na UTIN seja menos sofrida. Desse modo, contribuirá com sua participação ao longo da experiência, em caso de prolongamento da estadia no cuidado intensivo neonatal.

Torna-se fundamental também a organização de times de especialistas qualificados para a identificação de problemas de ordem cognitiva, afetiva e comportamental materna na primeira semana de hospitalização do RNPT na UTIN, além de identificação de suas forças e recursos utilizados em tempos difíceis, que possam ser traduzidos em intervenções capazes de promover mudanças profundas nos domínios afetados.

Aponta-se como limitação do estudo o fato de os dados não serem generalizáveis, visto contemplarem um único cenário de cuidado neonatal e suas singularidades. No entanto, considerando as particularidades locais das unidades neonatais dos hospitais em questão e do grupo social entrevistado, considera-se a possibilidade de sua generalização para esse contexto. 
Experiências maternas na primeira semana de hospitalização do prematuro em cuidado... $\mid 18$

Deste modo, a realização de pesquisas em outros contextos do cenário nacional poderá apontar distintos elementos sobre a experiência materna e demais familiares na primeira semana de hospitalização do RNPT na UTIN, contribuindo com possibilidades de intervenção e conhecimentos para o sustento da saúde familiar em tempos difíceis. Além disso, futuras pesquisas podem ser realizadas com maior extensão do tempo de coleta, pois, ao utilizar a saturação teórica, ${ }^{12}$ não se pode afirmar com precisão que outros dados não serão mais encontrados.

\section{Conclusão}

O estranhamento do ambiente novo, o temor diante do aparato do cuidado invasivo e a incerteza sobre o desfecho da situação crítica do RNPT foram causadores do sofrimento materno e proporcionaram o sentimento constante de medo da morte. Isso reforça a importância de acompanhar e apoiar a mãe durante a primeira semana de hospitalização do RNPT na UTIN, explicando-lhe sobre os dispositivos e tecnologias de suporte e como poderá participar de seu cuidado nesse momento, destacando sua presença para a recuperação do filho, bem como da inclusão de outros membros da família como suportes sociais e constantes em sua vida no cuidado intensivo neonatal.

\section{Referências}

1. Dagklis T, Papazisis G, Tsakiridis I, Chouliara F, Mamopoulos A, Rousso D. Prevalence of antenatal depression and associated factors among pregnant women hospitalized in a high-risk pregnancy unit in Greece. Soc Psychiatry Psychiatr Epidemiol. 2016;51(7):1025-31. doi: 10.1007/s00127-016-1230-7

2. Dagklis T, Tsakiridis I, Chouliara F, Mamopoulos A, Rousso D, Athanasiadis A, et al. Antenatal depression among women hospitalized due to threatened preterm labor in a high-risk pregnancy unit in Greece. J Matern Fetal Neonatal Med. 2018;31(7):919-25. doi: 10.1080/14767058.2017.1301926

3. Pulliainen H, Niela-Vilén H, Ekholm E, Ahlqvist-Björkroth S. Experiences of interactive ultrasound examination among women at risk of preterm birth: a qualitative study. BMC Pregnancy Childbirth. 2019;19(1):338. doi: 10.1186/s12884-019-2493-2 
4. Tsakiridis I, Bousi V, Dagklis T, Sardeli C, Nikolopoulou V, Papazisis G. Epidemiology of antenatal depression among women with high-risk pregnancies due to obstetric complications: a scoping review. Arch Gynecol Obstet. 2019;300(4):849-59. doi: 10.1007/s00404-019-05270-1

5. Veronez M, Borghesan NAB, Corrêa DAM, Higarashi IH. Vivência de mães de bebês prematuros do nascimento a alta: notas de diários de campo. Rev Gaúch Enferm. 2017;38(2):1-8. doi: 10.1590/19831447.2017.02.60911

6. Al Maghaireh DF, Abdullah KL, Chan CM, Piaw CY, Al Kawafha MM. Systematic review of qualitative studies exploring parental experiences in the Neonatal Intensive Care Unit. J Clin Nurs. 2016;25(19-20):2745-56. doi: 10.1111/jocn.13259

7. Baseggio DB, Dias MPS, Brusque SR, Donelli TMS, Mendes P. Vivências de mães e bebês prematuros durante a internação neonatal. Temas Psicol. 2017;25(1):153-67. doi: 10.9788/TP2017.1-10

8. Lima VF, Mazza VA, Mór LM, Pinto MNGR. Vivência dos familiares de prematuros internados em unidade de terapia intensiva neonatal. REME Rev Min Enferm. 2017;21:e1026. doi: 10.5935/14152762.20170036

9. Fernández Medina IM, Fernández-Sola C, López-Rodríguez MM, Hernández-Padilla JM, Manuel J, Jiménez Lasserrotte MM, et al. Barriers to providing mother's own milk to extremely preterm infants in the NICU. Adv Neonatal Care. 2019;19(5):349-60. doi: 10.1097/ANC.0000000000000652

10. Silva RMM, Menezes CCS, Cardoso LL, França AFO. Vivências de famílias de neonatos prematuros hospitalizados em Unidade de Terapia Intensiva Neonatal: revisão integrativa. Rev Enferm Cent Oeste Min. 2016;6(2):2258-70. doi: 10.19175/recom.v6i2.940

11. Ministério da Saúde (BR). Atenção à saúde do recém-nascido: guia para os profissionais de saúde 2a ed. atual. [Internet]. Brasília (DF): Ministério da Saúde; 2014 [acesso em 2020 maio 27]. Disponível em: http://bvsms.saude.gov.br/bvs/publicacoes/atencao_saude_recem_nascido_v1.pdf

12. Falqueto JMZ, Farias JS, Hoffmann VE. Saturação teórica em pesquisas qualitativas: relato de uma experiência de aplicação em estudo na área de administração. Rev Ciênc Adm (Florianópolis). 2018;20(52):40-53. doi: http://dx.doi.org/10.5007/2175-8077.2018V20n52p40

13. Bardin L. Análise de conteúdo. São Paulo: Edições 70; 2011.

14. Silva KC, Kerber NPC, Silva CSG, Christoffel MM, Carvalho ESS, Passos SSS, et al. Maternal experiences during hospitalization of premature newborn. Rev Soc Bras Enferm Pediatras (Online). 2019;19(1):7-15. doi: 10.31508/1676-3793201900002

15. Pereira LB, Abrão ACFV, Ohara CVS, Ribeiro CA. Vivências maternas frente às peculiaridades da prematuridade que dificultam a amamentação. Texto Contexto Enferm. 2015;24(1):55-63. doi: 10.1590/0104-07072015000540014 
Experiências maternas na primeira semana de hospitalização do prematuro em cuidado... $\mid 20$

16. Fernández Medina IM, Granero-Molina J, Fernández-Sola C, Hernández-Padilla JM, Camacho Ávila M, López Rodríguez MDM. Bonding in neonatal Intensive Care Units: experiences of extremely preterm infants' mothers. Women Birth. 2018;31(4):325-30. doi: 10.1016/j.wombi.2017.11.008

17. Akkoyun S, Arslan FT. Investigation of stress and nursing support in mothers of preterm infants in neonatal intensive care units. Scand J Caring Sci. 2019;33(2):351-8. doi: 10.1111/scs.12630

18. Lomotey AY, Bam V, Diji AKA, Asante E, Asante HB, Osei J. Experiences of mothers with preterm babies at a Mother and Baby Unit of a tertiary hospital: a descriptive phenomenological study. Nurs Open. 2019;7(1):150-9. doi: 10.1002/nop2.373

19. Kegler JJ, Neves ET, Silva AM, Jantsch LB, Bertoldo CS, Silva JH. Estresse em pais de recém-nascidos em uma Unidade de Terapia Intensiva Neonatal. Esc Anna Nery Rev Enferm. 2019;23(1):1-6. doi: 10.1590/2177-9465-EAN-2018-0178

20. Fróes GF, Mendes ENW, Pedroza GA, Cunha MLC. Estresse experimentado por mães de recémnascidos pré-termo em unidade de terapia intensiva neonatal. Rev Gaúch Enferm. 2020;41(N Esp):e20190145:1-10. doi: 10.1590/1983-1447.2020.20190145

21. Gonçalves JL, Fuertes M, Alves MJ, Antunes S, Almeida AR, Casimiro R, et al. Maternal pre and perinatal experiences with their full-term, preterm and very preterm newborns. BMC Pregnancy Childbirth. 2020;20(1):276. doi: 10.1186/s12884-020-02934-8

22. Carvalho LS, Pereira CMC. As reações psicológicas dos pais frente à hospitalização do bebê prematuro na UTI neonatal. Rev SBPH [Internet]. 2017 jul-dez [acesso em 2019 dez 03];20(2):101-22. Disponível em: http://pepsic.bvsalud.org/pdf/rsbph/v20n2/v20n2a07.pdf

23. Santos AS, Rodrigues LN, Santos MSN, Sousa GJB, Viana MCA, Chaves EMC. Papel materno durante a hospitalização do filho na Unidade de Terapia Intensiva Neonatal. Texto Contexto Enferm. 2019;28:e20180394. doi: 10.1590/1980-265X-TCE-2018-0394

24. Rolim KMC, Santiago NR, Vieira TL, Sancho MC, Frota MA, Boulard H, et al. Imaginário de mães acerca da hospitalização do filho na Unidade de Terapia Intensiva Neonatal. Enferm Foco [Internet]. 2016 [acesso em 2019 dez 03];7(1):42-6. Disponível em: http://revista.cofen.gov.br/index.php/enfermagem/article/view/664/283

25. Gomes IF, Oliveira JA, Lopes MR, Galdino MFG, Gesteira ECR, Braga PP. Vivências de famílias no cuidado à criança com complicações da prematuridade. Ciênc Cuid Saúde. 2016;15(4):630-8. doi: 10.4025/cienccuidsaude.v15i4.29959

26. Almeida CR, Morais AC, Lima KDF, Silva ACOC. Cotidiano de mães acompanhantes na unidade de terapia intensiva neonatal. Rev Enferm UFPE On Line [Internet]. 2018 [cited 2019 Dec 03];12(7):1949-56. Available from: https://periodicos.ufpe.br/revistas/revistaenfermagem/article/view/22640 
27. Sampaio PSS, Angelo M. Cuidado da família em pediatria: vivências de enfermeiros em um Hospital Universitário. Rev Soc Bras Enferm Pediatras [Internet]. 2015 [acesso em 2019 dez 03];15(2):85-92. Disponível em: https://sobep.org.br/revista/images/stories/pdf-revista/vol15-n2/vol_15_n_2-artigo-depesquisa-1.pdf

\section{Autor correspondente}

Cinthia Reis Almeida

E-mail: cinthiialmeida@gmail.com

Endereço: Travessa Eloy Guimarães, n03, apto 202, Edf Barreiros, Bairro Tororó.

CEP: 40050080

\section{Contribuições de Autoria}

1 - Cinthia Reis Almeida

Coleta, análise, interpretação dos dados. Revisão final com participação crítica e intelectual no manuscrito

\section{2 - Evanilda Souza de Santana Carvalho}

Interpretação dos dados. Revisão final com participação crítica e intelectual no manuscrito.

\section{3 - Silvia da Silva Santos Passos}

Revisão final com participação crítica e intelectual no manuscrito.

\section{4 - Flávia Pimentel Miranda}

Revisão final com participação crítica e intelectual no manuscrito.

\section{5 - Luciano Marques dos Santos}

Concepção do estudo. Análise e interpretação dos dados. Revisão final com participação crítica e intelectual no manuscrito.

\section{Como citar este artigo}

Almeida CR, Carvalho ESS, Passos SSS, Miranda FP, Santos LM. Experiências maternas na primeira semana de hospitalização do prematuro em cuidado intensivo. Rev. Enferm. UFSM. 2020 [Acesso em: Anos Mês Dia]; vol.10 e75: 1-21. DOI:https://doi.org/10.5902/2179769242072 